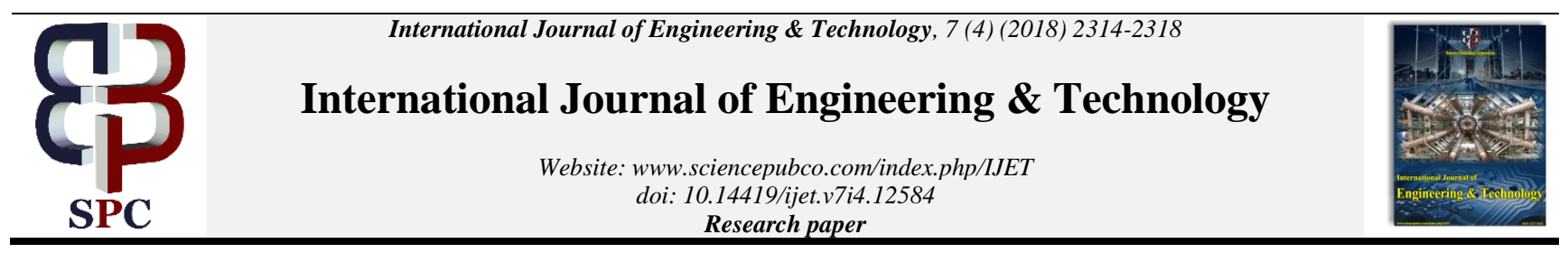

\title{
The economic benefit analysis to the consumer and utility due to PV generation connected to the radial distribution system
}

\author{
G. Lincy ${ }^{1 *}$, Dr. M. Ponnavaikko ${ }^{2}$, Dr. Lenin Anselm W. A. ${ }^{3}$ \\ ${ }^{1}$ Research Scholar, Bharath University, Department of Electrical and Electronics Engineering, Chennai-600073, India \\ ${ }^{2}$ Provost, Vinayaka Missions University, Paiyanoor-6030073, Kanchipuram District, India \\ ${ }^{3}$ Lecturer, Shinas college of technology, Shinas, Sultanate of Oman, P. O. Box 77 PC 324 \\ *Corresponding author E-mail: lincy.lincy062@gmail.com
}

\begin{abstract}
During the recent past, the interest towards adoption of Distributed Generation (DG) has increased dramatically among the electric power system utilities. It has been well established that installation of PV Generation at the load points in a distribution system is excellent advantages for both consumers and the utilities. The question arises whether the maximum beneficiary is the Utility or the consumer and who has to bear the cost. This research analyses the economics of the DG with PV Systems, taking a typical 400V distribution system. A detailed procedure adopted for performing the economic analysis is presented in this paper. Benefits considered includes Saving in the energy losses, Energy substitute by the PV system, Capacity release in the Feeders and the Transformer. The PV system is installed at the selected consumer load points, based on the size and location of the loads. Discounted Cash Flow technique is used to assess the economics of the system, by computing the Internal Rate of Return. The paper presents the advantages of using PV Generating systems in the Power Distribution System, quantifying economic benefits both for the Utilities and for the Customers with supporting data.
\end{abstract}

Keywords: Photovoltaic(PV); Distributed Generation (DG); Micro Grid; Smart Grid; Discounted Cash Flow; IRR; Distribution System.

\section{Introduction}

The Distributed Generation(DG) is an essential concept in the power distribution system and is of great interest to the stakeholders in the electrical energy supply industries today. The Distributed generation is widely used in many countries around the world. J.A Pecas Lopes et al. say that the distributed generation reduces the greenhouse gas emission and avoids the construction of new transmission circuits and large generating plants. It is a low cost small generating unit and improves the power quality and reliability. This paper has considered Diesel Generating sets as Distributed Generation and not the PV system [1]. Dr. C. K. Chanda et al. discusses the economic index of Herfindahl-Hirschman index to know about the competition of DG in India. It is a measurement used to measure the level of competition available in the market or industry. As the number of DG increase Herfindahl-Hirschman index value decreasing, it shows the competition in the market. The deregulation plan in India got cheaper power rather than other. The installation of DG reduces the cost because of loss reduction, imported fuels and greenhouse gas emission [2]. Paul Westacott discusses the impact of photovoltaic penetration across an entire low-voltage distribution network containing 1.5 million customers. With the installation of PV, $20 \%$ in the low voltage network reduces the power flow from HV (High voltage) to LV (Low voltage) [3]. The potential impact of PV panels in New Zealand has been investigated by Jermy D. Watson, et al. The PV in the low voltage network creates overvoltage and reverse power flow problem. The overvoltage problems are mitigated by line drop compensation. It does not talk about the improvement of voltage sag problems in the distribution system [4]. S. Porkar et al. discusses the impact of DG on IEEE 30 -BUS system, and the voltage is $33 \mathrm{kV}$. The main aim of this work is to minimization cost and maximization of social welfare. The social welfare is the total costs of the system before and after system upgrading. The payback time is discussed to improve the welfare of the society. The main aim of optimal placement is to reduce the loss cost, implementation of the circuit breaker, electricity purchase. DG improves the power quality technical and economic factors [5]. Sang-Seung Lee develops a new framework for South Korean power distribution system with the implementation of smart/microgrids. The State Business Unit (SBU) map was subdivided into nine strategic business units. These business units improve the profit and the efficiency [6]. Naveen Ahmed Khan discusses the combined emission economic dispatch for solar integrated power systems. This work concentrates on the solar PV integrated power system which could minimize the fuel cost, emission and could maximize the solar share and the number of solar plants. The constraints of power balance and the bounds on generators, renewable energy, voltage magnitude, transformer taps, and line capacitors were considered in the joint optimization problem [7]. Badrul H. Chowdhury et al. discusses the Benefit of PV installation in the Distribution system. The PV system gives the voltage support and reduces the losses in the distribution system. The use of PV in the Distribution system saving the energy cost, loss reduction revenue and saving from avoided var device placement. So, it reduces the installation of capacitor banks and voltage regulators [8]. A.P Agalgaonkow et al. presents their study on the planning of a typical medium-voltage rural distribution system in the state of Maharashtra, India, considering different loading conditions and different attributes, like capital costs, energy that not 
served per annum, and profits from injecting power into the grid during peak load. A new concept of the composite utility function is proposed for getting information about infeasible values of different attributes [9]. Hugo A. Gil et al. discusses the economic benefit of customer, Power system operator and society benefit and distribution utility benefit with the connection of DG. The customer benefit is the reliability and reduces the electricity bill. The utility benefit is the upgrade deferral benefit, avoid electricity purchase and loss reduction [10]. N. Rugthaicharoencheep et al. discusses the technical and economic impacts of Distributed Generation on Distribution System. The technical impact is power loss to the system reduces, improves the power quality, improves the reliability of the system. The distributed generation reduces the power flow in the transmission line. It reduces the power loss in the transmission line. DG reduces the cost of the energy, independent of the imported fuel, increase the new industry and additional employment. [11].

This study aims to provide certain guiding principles for the adoption of PV Systems at the load points in the distribution system, regarding economic benefits to the utilities as well as to the consumers. The guiding principles are derived based on specific studies carried out on a typical Distribution system in Kanchipuram District, Tamil Nadu, India. This paper also presents simplified methods to calculate the nodal voltages and the power and energy losses in the feeders as well as to determine the economic benefits regarding Internal Rate of Return (IRR).

\section{Distribution system with installed PVS at load points}

This paper presents the study conducted for a distribution system with the solar system connected to the loads directly. The system studied is a $400 \mathrm{~V}$ Distribution system having 54 loads, including Domestic, Agricultural and Industrial consumers of varying loads, amounting to $80.53 \mathrm{~kW}$, fed by a $100 \mathrm{kVA}$ Distribution Transformer through two feeders as shown in Fig.1. From SS to A iris conductor is used, SS to B mink conductor is used, and other places rose conductor is used. Connecting a load directly to the PV System results with the following benefits.: (i) Saving of Energy losses in the feeder and the Transformer. (ii) Capacity release in the feeder and Transformer, to meet the load growth in the system without augmentation of the feeder or the Transformer capacity. (iii) Energy supplied by the PV System. (iv) The improvement in voltage level in the nodes of load points.

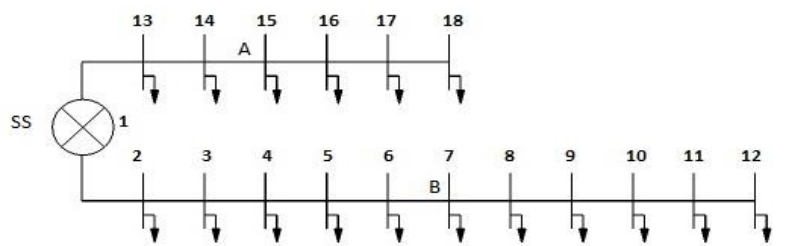

Fig. 1: A 400V distribution system with two feeders.

Table 1: Load Data of the Test System

\begin{tabular}{llllll}
\multicolumn{7}{c}{ Table 1: Load Data of the Test System } \\
\hline BUS & 2 & 3 & 4 & 5 & 6 \\
\hline P[kW] & 2.238 & - & 12.628 & 0.520 & 3.73 \\
BUS & 7 & 8 & 9 & 10 & 11 \\
P[kW] & 3.73 & 4.476 & 2.238 & 2.238 & 3.730 \\
BUS & 12 & 13 & 14 & 15 & 16 \\
P[kW] & 2.238 & 4.370 & 0.080 & 17.278 & 13.37 \\
BUS & 17 & 18 & & & \\
P[kW] & 2.238 & 2.238 & & & \\
\hline
\end{tabular}

Table 2: Resistance and Reactance values of the Test System

\begin{tabular}{lllll}
\hline LINE & $1-2$ & $2-3$ & $3-4$ & $4-5$ \\
\hline Resistance $(\Omega)$ & 0.0194 & 0.0235 & 0.1170 & 0.0306 \\
LINE & $5-6$ & $6-7$ & $7-8$ & $8-9$ \\
Resistance $(\Omega)$ & 0.03066 & 0.0996 & 0.2646 & 0.2044 \\
LINE & $9-10$ & $10-11$ & $11-12$ & $13-14$ \\
Resistance $\Omega)$ & 0.165 & 0.644 & 0.1064 & 0.152 \\
LINE & $14-15$ & $15-16$ & $16-17$ & $17-18$ \\
Resistance $(\Omega)$ & 0.152 & 0.13832 & 0.1383 & 0.1938 \\
\hline
\end{tabular}

To assess the economic benefits in integration of PV System, the following three cases were studied: (i) A feeder feeding one of the far ends $3 \mathrm{hp}$ loads directly by the PV System (Fig.2). (ii) A feeder is feeding one of the far ends $5 \mathrm{hp}$ loads directly by the PV System (Fig.3). A feeder is feeding one of the far ends $15 \mathrm{hp} \mathrm{loads} \mathrm{directly}$ by the PV System (Fig.4). For all the three cases, the above said benefits are assessed, and the Internal Rate of Return (IRR) using the Discounted Cash Flow technique is computed to know the economic benefit of PV Integration.

Methods used to calculate the nodal voltages, the power, and energy losses in the feeder and IRR are detailed below:

\subsection{Nodal voltage calculation}

Nodal voltages are calculated using the voltage regulation constant, $\mathrm{H}$, defined by the authors in their paper [12] as Load moment for $1 \%$ of voltage drop in the feeder, given in (1)

$H=\frac{10(k V)^{2}}{r \cos \theta+x \sin \theta}$

Where

$\mathrm{KV}$ is the average circuit voltage,

$\mathrm{R}$ and $\mathrm{x}$ are the resistance and reactance per

$\mathrm{Km}$ of the conductor used and

$\theta$ is the power factor angle of the load flow

The percentage of voltage regulation is given by

$$
\mathrm{V}=\mathrm{M} / \mathrm{H}
$$

Where,

$\mathrm{M}$ is the total load moment of the feeder in km-KVA.

The load moments are calculated in km-kVA for the main feeder sections. The resistance and reactance values of the conductors used in the feeder are given in Table 1The power factor angle is taken as 0.8 , and the average circuit voltage is taken as $0.400 \mathrm{kV}$.

\subsection{Power \& energy loss calculation}

The power loss, PL in the feeder sections is calculated using (3)

$\mathrm{PL}=3 \mathrm{I}^{\wedge} 2 \mathrm{R} / 1000$ kilo Watts

Energy Loss, EL is calculated using

$\mathrm{EL}=\mathrm{PL} \times \mathrm{LLF} \times 8760$ units

Where LLF is a function of load factor and is defined as

$$
L L F=A(L F)^{2}+B(L F)
$$

Moreover, $\mathrm{A}+\mathrm{B}=1$

As per British formula, $\mathrm{A}=0.8$ and $\mathrm{B}=0.2$

\subsection{Economic analysis}

The economic analysis of PV system integration is assessed regarding IRR. IRR is that rate of interest at which the Cash Outflow equals to Cash Inflow.

Cash Outflow is the sum of the initial investment in year $1+$ the present worth of $\mathrm{O} \& \mathrm{M}$ charges spent every year during the life cycle.

Cash Inflow is the sum of the present worth of (i) cost of Saving of Energy losses in the feeder and in the Transformer, (ii) the cost of Energy released in the feeder and Transformer capacity to meet the load growth in the system without augmentation of the feeder or the Transformer capacity, and (iii) cost Energy supplied by the PV System every year during the life cycle of the PV System. 
The formula used for computing the present worth $\mathrm{Pw}$ of future value $(\mathrm{FV})$ is given by (7).

$\mathrm{Pw}=\mathrm{FV} / \llbracket(1+\mathrm{i}) \rrbracket \wedge \mathrm{n}$

Where, ' $\mathrm{I}$ ' is the rate of interest and $\mathrm{n}$ is the year of future value points.

\section{Case studies}

Case 1: A feeder feeding a $3 \mathrm{hp} \mathrm{load}$ at node No.12, directly by the PV System (Fig.2.)

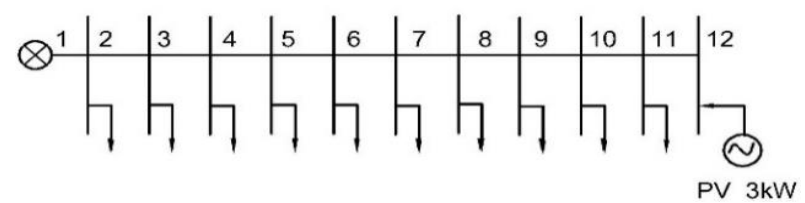

Fig. 2: Main Feeder- 1 with A PV System at Node 12 to Feed A 3 Hp Load.

- The lowest level of the voltage obtained at node No. 12 without PV installed, is $306 \mathrm{~V}$.

- The lowest level of the voltage obtained at node 11 with PV installed at node 12 , is $325 \mathrm{~V}$.

- Power loss in the feeder without PV is 6,208.3341W.

- Power loss in the feeder with PV is 4,421.296471W.

- Saving in power loss with PV is $2287.0376 \mathrm{~W}$

- Energy loss in the feeder without PV is $16,315.5038$ Units.

- Energy loss in the feeder with PV is 11,619.16713Units.

- Saving in Energy loss every year with PV is 4696.34Units.

- Cost of Energy saved every year is Rs.23528.66.

- Energy supplied by PVs during every year is given in Table 3.

- Capacity release in the feeder and Transformer, to meet the load growth in the system without augmentation of the feeder or the Transformer capacity is $2,238 \mathrm{~W}$.

- Additional energy that could be fed; due to the capacity release of $2,238 \mathrm{~W}$ in the feeder and Transformer at $50 \%$ load factors 9,802 units.

- Revenue realizable per year due to the sale of additional energy is Rs. 49108.

- $\quad$ Energy supplied by the PV System is 4,467units.

- Capital investment for installing $3 \mathrm{kWp}$ PV System is Rs. 251250.00 .

- Annual O\& M charges for the PV System is Rs.2000.00.

Revenue to the customers:

Cash outflow to the customer during the life of the PV system which includes the capital investment in the first year and the O\& $M$ charges every year is given is given in Table 4 . Cost of energy supplied by PV is shown in table 5. Cash inflow to the customers in a year, $i$, is $=100500(40 \%$ of the PV investment cost $)+$ cost of energy supplied by PV in the year, i. IRR of the investment to the customers is $10.5 \%$.

Revenue to the utility:

Cash outflow to the utility during the life of the PV system which includes the capital investment in the first year and the O\& M charges every year is given is given in Table 4. Cash Inflow to the utility during the life of the PV system which includes the Revenue due to the energy saved and energy supplied by the PV System every year is given in Table 5. Cash inflow to the utility in the year, $i$, is equal to annual cost of loss saving is Rs.23528.66 + cost of energy supplied by PV in the year, i+ Revenue realizable per year due to the sale of additional energy is Rs.49108. IRR of the investment is $37.5 \%$.

Table 3: Energy Supplied by the PV System (Case 1)

\begin{tabular}{llll}
\hline \multirow{2}{*}{ Year } & $\begin{array}{l}\text { Energy supplied by PV } \\
\text { System (Units) }\end{array}$ & Year & $\begin{array}{l}\text { Energy supplied by PV } \\
\text { System (Units) }\end{array}$ \\
\hline 1 & 4467 & 14 & 3920 \\
2 & 4422 & 15 & 3881 \\
3 & 4378 & 16 & 3842 \\
\hline
\end{tabular}

\begin{tabular}{llll}
\hline 4 & 4334 & 17 & 3803 \\
5 & 4291 & 18 & 3765 \\
6 & 4248 & 19 & 3728 \\
7 & 4206 & 20 & 3690 \\
8 & 4164 & 21 & 3654 \\
9 & 4122 & 22 & 3617 \\
10 & 4081 & 23 & 3581 \\
11 & 4040 & 24 & 3545 \\
12 & 3999 & 25 & 3510 \\
13 & 3959 & & \\
\hline
\end{tabular}

Table 4: Cash Outflow (Case -1)

\begin{tabular}{llll}
\hline year & Cost(Rs) & year & Cost(Rs) \\
\hline 1 & 253250 & 2 to 25 every year & 2000 \\
\hline
\end{tabular}

\begin{tabular}{llll}
\multicolumn{5}{c}{ Table 5: Cost of Energy } & Supplied by PV (Case 1) \\
\hline \multirow{2}{*}{ Year } & $\begin{array}{c}\text { Cost of energy sup- } \\
\text { plied by PV (in Rs) }\end{array}$ & Year & $\begin{array}{l}\text { Cost of energy sup- } \\
\text { plied by PV (in Rs) }\end{array}$ \\
\hline 1 & 22379.67 & 14 & 19639.20 \\
2 & 22154.22 & 15 & 19443.81 \\
3 & 21933.78 & 16 & 19248.42 \\
4 & 21713.34 & 17 & 19053.03 \\
5 & 21497.91 & 18 & 18862.65 \\
6 & 21282.48 & 19 & 18677.00 \\
7 & 21072.06 & 20 & 18486.90 \\
8 & 20861.64 & 21 & 18306.54 \\
9 & 20651.22 & 22 & 18121.17 \\
10 & 20445.81 & 23 & 17940.81 \\
11 & 20240.40 & 24 & 17760.45 \\
12 & 20034.99 & 25 & 17585.10 \\
13 & 19834.59 & & \\
\hline
\end{tabular}

Case 2: Feeding a 5hp load at node 11, directly by the PV System (Fig.3)

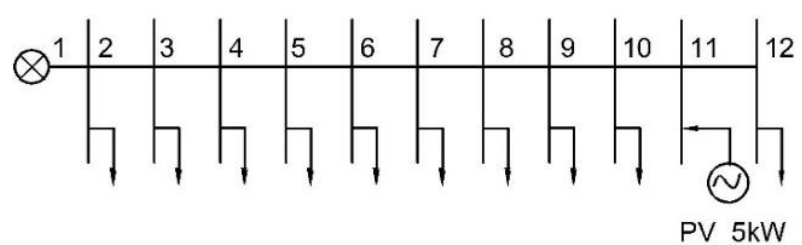

Fig. 3: Main Feeder - 1 With A PV System at Node 11 To Feed A 5 Hp Load.

- The lowest level of voltage was obtained at node No. 12 without PV installed is $306 \mathrm{~V}$.

- The lowest level of voltage was obtained at node No. 12 with $\mathrm{PV}$ installed is $335.7 \mathrm{~V}$.

- Power loss in the feeder without PV is $6,208.33 \mathrm{~W}$.

- Power loss in the feeder with PV is 3,680.33W.

- Saving in power loss with PV is 2,528.32W.

- Energy loss in the feeder without PV is $16,315.50381$ Units.

- Energy loss in the feeder with PV is 9,671.06628Units.

- Saving in Energy loss with PV every year is 6,644Units.

- Cost of Energy saved every year is Rs.33286.44.

- Energy supplied by the PV System every year is given in Table 6 .

- Capacity release in the feeder and Transformer, to meet the load growth in the system without augmentation of the feeder or the Transformer capacity is $3,730 \mathrm{~W}$.

- Additional energy that could be fed due to the capacity release of $3,730 \mathrm{~W}$ in the feeder and Transformer at $50 \%$ load factor is 16,337 units.

- Capital investment for installing $5 \mathrm{kWp} \mathrm{PV} \mathrm{System} \mathrm{is}$ Rs. 418750

- Annual O\& M of the PV System Rs.2000.

Revenue to the customers:

Cash outflow to the customer during the life of the PV system which includes the capital investment in the first year and the O\& M charges every year is given is given in Table 7. Cost of energy supplied by PV is shown in table 8. Cash inflow to the customers in a year, $i$, is $=167500(40 \%$ of the investment PV cost $)+$ cost of energy 
supplied by PV in the year, i. IRR of the investment to the customers is $11.5 \%$.

Revenue to the utility:

Cash outflow to the utility during the life of the PV system which includes the capital investment in the first year and the O\& M charges every year is given is given in Table 7. Cash Inflow to the utility during the life of the PV system which includes the Revenue due to the energy saved and cost of energy supplied by the PV System every year is given in Table 8 . Cash inflow to the utility in the year, $i$, equal to the annual cost of loss saving is Rs.33286.44 + cost of energy supplied by PV in the year, i+ Revenue realizable per year due to the sale of additional energy is Rs.81848. IRR of the investment to the utility is $35.7 \%$.

Table 6: Energy Supplied by the PV System (Case 2)

\begin{tabular}{llll}
\hline Year & $\begin{array}{l}\text { Energy supplied by } \\
\text { PV(Units) }\end{array}$ & Year & $\begin{array}{l}\text { Energy supplied by } \\
\text { PV(Units) }\end{array}$ \\
\hline 1 & 7445 & 14 & 6533 \\
2 & 7371 & 15 & 6468 \\
3 & 7297 & 16 & 6403 \\
4 & 7224 & 17 & 6339 \\
5 & 7152 & 18 & 6276 \\
6 & 7080 & 19 & 6213 \\
7 & 7009 & 20 & 6151 \\
8 & 6939 & 21 & 6089 \\
9 & 6870 & 22 & 6028 \\
10 & 6801 & 23 & 5968 \\
11 & 6733 & 24 & 5908 \\
12 & 6666 & 25 & 5849 \\
13 & 6599 & & \\
\hline
\end{tabular}

Table 7: Cash Outflow (Case 2)

\begin{tabular}{|c|c|c|c|}
\hline Year & Cost(Rs) & Year & Cost(Rs) \\
\hline 1 & 420750 & 2 to 25 every year & 2000 \\
\hline
\end{tabular}

Table 8: Cost of Energy Supplied By PV (Rs) (Case 2)

\begin{tabular}{llll}
\hline Year & $\begin{array}{l}\text { Cost of energy sup- } \\
\text { plied by PV(Rs) }\end{array}$ & $\begin{array}{l}\text { Cost of energy sup- } \\
\text { plied by PV(Rs) }\end{array}$ \\
\hline 1 & 37299.45 & 14 & 32730.33 \\
2 & 36928.71 & 15 & 32404.68 \\
3 & 36557.97 & 16 & 32079.03 \\
4 & 36192.24 & 17 & 31758.39 \\
5 & 35831.52 & 18 & 31442.76 \\
6 & 35470.80 & 19 & 31127.13 \\
7 & 35115.09 & 20 & 30816.51 \\
8 & 34764.39 & 21 & 30505.89 \\
9 & 34418.70 & 22 & 30200.00 \\
10 & 34073.01 & 23 & 29899.00 \\
11 & 33732.33 & 24 & 29599.08 \\
12 & 33396.66 & 25 & 29303.49 \\
13 & 33060.99 & & \\
\hline
\end{tabular}

Case -3 : Feeding a 15 hp load at node No.16, directly by the PV System (Fig.4)

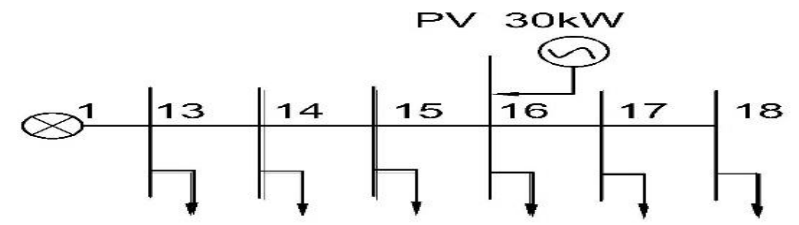

Fig. 4: Main Feeder- 2 with A PV System at Node 16 to Feed A 15 Hp Load.

- The lowest level of voltage was obtained at node No. 16 without PV installed is $310 \mathrm{~V}$.

- $\quad$ The lowest level of voltage was obtained at node No. 15 with $\mathrm{PV}$ installed is $393 \mathrm{~V}$.

- Power loss in the feeder without PV is $6,874.22 \mathrm{~W}$

- Power loss in the feeder with PV is $1941.42475 \mathrm{~W}$.

- Saving in power loss with PV is $4,932.8 \mathrm{~W}$.

- Energy loss in the feeder without PV is 18,065 Units

- Energy loss in the feeder with PV is 5,102.06 Units.

- Energy loss reduction with PV every year is12,963.385Units.

- Cost of Energy saved every year is Rs.64946.5338
- Capacity release in the feeder and Transformer, to meet the load growth in the system without augmentation of the feeder or the Transformer capacity.is $22,380 \mathrm{~W}$.

- Additional energy that could be fed due to the capacity release of $22,380 \mathrm{~W}$ in the feeder and Transformer at $50 \%$ load factor is 98,024 units.

- Revenue realizable per year due to the sale of additional energy is Rs. 491100.

- $\quad$ Energy supplied by the PV System is given in Table 9

- Capital investment for installing two numbers of $15 \mathrm{kWp}$ PV System is Rs. 2596000.

- Annual O\& M of the PV System Rs.4000.

Revenue to the customers:

Cash outflow to the customer during the life of the PV system which includes the capital investment in the first year and the O\& $\mathrm{M}$ charges every year is given is given in Table 10. Cost of energy supplied by PV is shown in table 11. Cash inflow to the customers in a year, $\mathrm{i}$, is $=1118400(40 \%$ of the PV investment cost $)+$ cost of energy supplied by PV in the year, i. IRR of the investment to the customers is $15.2 \%$.

Revenue to the utility:

Cash outflow to the utility during the life of the PV system which includes the capital investment in the first year and the O\& M charges every year is given is given in Table 10. Cash Inflow to the utility during the life of the PV system which includes the Revenue due to the energy saved and cost of energy supplied by the PV System every year is given in Table 11. Cash inflow to the utility in the year, $i$, equal to the annual cost of loss saving is Rs.64946.533 + cost of energy supplied by PV in the year, i+ Revenue realizable per year due to the sale of additional energy is Rs.491100. IRR of the investment to the utility is $26.2 \%$.

Table 9: Energy Supplied by the PV System (Case 3)

\begin{tabular}{llll}
\hline Year & $\begin{array}{l}\text { Energy supplied by PV } \\
\text { (Units) }\end{array}$ & Year & $\begin{array}{l}\text { Energy supplied by PV } \\
\text { (Units) }\end{array}$ \\
\hline 1 & 44550 & 14 & 39094 \\
2 & 44104 & 15 & 38702 \\
3 & 43664 & 16 & 38316 \\
4 & 43226 & 17 & 37932 \\
5 & 42794 & 18 & 37554 \\
6 & 42366 & 19 & 37178 \\
7 & 41942 & 20 & 36806 \\
8 & 41524 & 21 & 36438 \\
9 & 41108 & 22 & 36074 \\
10 & 40698 & 23 & 35712 \\
11 & 40290 & 24 & 35356 \\
12 & 39888 & 25 & 35002 \\
13 & 39488 & & \\
\hline
\end{tabular}

Table 10: Cash Outflow (Case 3)

\begin{tabular}{llll}
\hline Year & Cost(Rs) & Year & Cost(Rs) \\
\hline 1 & 2600000 & 2 to 25 every year & 4000 \\
\hline
\end{tabular}

Table 11: Cost of Energy Supplied by PV (Rs) (Case 3)

\begin{tabular}{llll}
\hline Year & $\begin{array}{l}\text { Cost of energy supplied } \\
\text { by PV(Rs) }\end{array}$ & Year & $\begin{array}{l}\text { Cost of energy supplied } \\
\text { by PV(Rs) }\end{array}$ \\
\hline 1 & 223195.50 & 14 & 195860.94 \\
2 & 220961.04 & 15 & 193897.02 \\
3 & 218756.64 & 16 & 191963.16 \\
4 & 216562.26 & 17 & 190039.32 \\
5 & 214397.94 & 18 & 188145.54 \\
6 & 212253.66 & 19 & 186261.78 \\
7 & 210129.42 & 20 & 184398.00 \\
8 & 208035.24 & 21 & 182554.38 \\
9 & 205951.08 & 22 & 180730.74 \\
10 & 203896.98 & 23 & 178917.12 \\
11 & 201852.90 & 24 & 177133.56 \\
12 & 199838.88 & 25 & 175360.02 \\
13 & 197834.88 & & \\
\hline
\end{tabular}




\section{Discussion of the results}

This research aimed to assess the benefits to the utility as well as to the customer independently, due to the installation of PV Systems at the load points directly. The investment gives a good Internal Rate of Return. In the case of Utility, there is an additional benefit of capacity release in the feeders and in the Transformer to meet the load growth in the system without augmentation of the feeder or the Transformer capacity. This gives an additional revenue from the sale of additional energy that could be fed to the new customers, due to a capacity release. If this additional financial benefit is accounted for in the economic analysis, the IRR works out to be very high. This shows that investing in the installation of PV Systems in the Distribution systems is an attractive proposition for the Utilities, particularly when installed at the far end of the Distribution feeders and in the isolated communities.

In the case of Customers, in addition to the high return on the in vestment, the voltage level is improved to the desired level, no problem of voltage fluctuation, high reliability of supply availability and no problem of supply availability during Feeder or Transformer outages or during system Blackouts. Also, the Electricity Boards give subsidy to the customers for the use of alternative source of energy like PV Systems.

The economic benefits assessed in the three cases studied are detailed below:

In Case (1) the investment of Rs.301, 250 gives an Internal Rate of Return to the customer of $10.5 \%$. The investment can be taken back in 7 to 8 years. IRR of return to the utility is $37.5 \%$. In this case, the investment can be taken back in 3 to 4 years.

In Case (2) the investment of Rs.468250 gives an Internal Rate of Return to the customer of $11.5 \%$. The investment can be taken back in 7 to 8 years. IRR of return to the utility is $35.7 \%$. In this case, the investment can be taken back in 3 to 4 years.

In Case (3) the investment Rs.2696000 gives an Internal Rate of Return to the customer of $15.2 \%$. The investment can be taken back in 6 to 7 years. IRR of return to the utility is $26.2 \%$. In this case, the investment can be taken back in 4 to 5 years.

\section{Conclusion}

It is evident that installation of PV Systems in the distribution network is economically beneficial to the Utility as well as to the Consumer as established in many countries through their experience. This confirmed through our studies as discussed above. Installation of PV systems at the load points or on the feeder is an added resource to the power system network to meet the growing demand in the power system network. Particularly when the coal reserves are getting exhausted, alternative sources of energy like solar, wind, etc. need to be exploited for meeting the demand in the system, economically and efficiently. The results of this investigation confirm that Utilities like Electricity Boards will be highly benefitted if they encourage the LT and HT Industrial consumers to install Solar power stations at their points of consumption through suitable subsidy schemes. The affordable Domestic and Agriculture consumers will be free from power quality problems if they install PV Systems at their load points and will harvest the other benefits discussed above.

Though the benefits of Distributed Generating Systems using PV Generation is well known, even now the distribution Engineers do not have simple guidelines to identify the load locations and isolated consumer communities on the economic aspects. This work presents a simple yet comprehensive decision-making tool for stakeholders interested in setting up a sustainable rural electrification project with PV Systems.

\section{References}

[1] Lopes, JA Pecas, N. Hatziargyriou, J. Mutale, P. Djapic, and N. Jenkins (2007), Integrating distributed generation into electric power systems: A review of drivers, challenges and opportunities. Electric power systems research 77, no. 9, 1189-1203. https://doi.org/10.1016/j.epsr.2006.08.016.

[2] Chanda, C. K., and Avishek Ghose Roy (2013), Assessment of Distributed Generation in a Deregulated Power Market Scenario in India In Presented at International Conference on Energy Resources and ICERSTD2013, vol. 13, no. 122, p. 122.

[3] Westacott, Paul, and Chiara Candelise (2016) Assessing the impacts of photovoltaic penetration across an entire low-voltage distribution network containing 1.5 million customers. IET Renewable Power Generation 10, no. 4, 460-466. https://doi.org/10.1049/ietrpg.2015.0535.

[4] Watson, Jeremy D., Neville R. Watson, David Santos-Martin, Alan R. Wood, Scott Lemon, and Allan JV Miller (2016), Effect of solar photovoltaics on the low-voltage distribution network in New Zealand. IET Generation, Transmission \& Distribution 10, no. 1 (2016): 1-9. https://doi.org/10.1049/iet-gtd.2014.1076.

[5] Porkar, S., A. Abbaspour-Tehrani-fard, P. Poure, and S. Sadat (2010), a multistage model for distribution expansion planning with distributed generation in a deregulated electricity market. Iranian Journal of Science and Technology 34, no. B3, 275.

[6] Lee, Sang-Seung, Sang-Ho Ahn, Joon-Hyung Park, Jae-HaengHeo, Dong-Hyeon Kim, Jong-Keun Park, Min-Uk Yang, Kern-Joong Kim, and Yong Tae Yoon (2012), South Korean power distribution system-based operation, market structure and regulation strategies under distributed generation and smart grid. In Power and Energy Society General Meeting, 2012 IEEE, pp. 1-7. IEEE

[7] Khan, Naveed Ahmed, Guftaar Ahmad Sardar Sidhu, and Feifei GAO (2016), Optimizing Combined Emission Economic Dispatch for Solar Integrated Power Systems. IEEE Access 4, 3340-3348.

[8] Chowdhury Badrul H. and Abdul W. Sawab (1996), "Evaluating the value of distributed photovoltaic generations in radial distribution systems." IEEE Transactions on Energy Conversion 11, no. 3, 595600. https://doi.org/10.1109/60.537030.

[9] Agalgaonkar, A. P., S. V. Kulkarni, and S. A. Khaparde (2006), Evaluation of configuration plans for DGs in developing countries using advanced planning techniques. IEEE Transactions on Power Systems 21, no. 2, 973-981. https://doi.org/10.1109/TPWRS.2006.873420.

[10] Gil, Hugo A., and Geza Joos (2008), Models for quantifying the economic benefits of distributed generation. IEEE Transactions on Power Systems 23, no. 2, 327-335. https://doi.org/10.1109/TPWRS.2008.920718.

[11] Rugthaicharoencheep, N., and S. Auchariyamet (2012). Technical and economic impacts of distributed generation on distribution system. World Academy of Science, Engineering and Technology 64.

[12] M. Ponnavaikko and Dr.K.S. Prakasa Rao (1984). Development of Nomograms for Power loss determination in Radial Distribution Feeders. Paper presented at the IEEE/PES 1984 Transmission and Distribution Conference, Kansas City, Missouri, April 29 -May 4, 1984. 